\title{
Adaptability and Workplace Subjective Well-Being: The Effects of Meaning and Purpose on Young Workers in the Workplace
}

\author{
Harry G. Nejad \\ O.P Jindal Global University of Behavioural Sciences \\ Fara G. Nejad \\ Athabasca University \\ Tara Farahani \\ University of Toronto
}

\begin{abstract}
Adaptability is described as the apt mental, behavioral, and/or emotional modifications individuals make to deal with change, challenges, and uncertainty. The present paper builds on the recently developed measurement work of the adaptability construct, investigates the relationship between adaptability and meaning and purpose (a well-being factor), and the role of adaptability in predicting workplace subjective well-being (work engagement, job satisfaction, and handling work stress) relevant to the young workforce. The adaptability study concluded that implicit theories and personality significantly projected adaptability. Further, adaptability is shown as the predictor of well-being (including meaning and purpose) after accounting for the effects of presage factors. These results presume implications for executives and practitioners pursuing to identify and address young workers' approaches to their challenging and adverse workplace demands, and how meaning and purpose may assist these workers in better adjustment and engagement in their workplace.
\end{abstract}

Keywords: adaptability, meaning and purpose, workplace, subjective well-being, work stress

Change is a constant factor in the human lifespan. The world endures substantial changes concerning environmental, social, educational, industrial, medical, and other spheres (Bronfenbrenner, 2001; Hofäcker, Buchholz, \& Blossfeld, 2010; Tomasik, Silbereisen, \& Heckhausen, 2010). Certainly, peoples' lives will be typified by recurrent novelty, variability, and uncertainty including some major transitional milestones such as beginning school, adapting to new peer groups, adapting to new jobs and co-workers, being married or in partnership, child-rearing, and retirement. Individuals also need to deal with minor transitional features including the mundane daily tasks in the workplace that can potentially shift habits and create new conditions which people must become familiar and comfortable with (Pinquart \& Silbereisen 2004; Tomasik \& Silbereisen 2009; Tomasik et al., 2010) or otherwise face adverse consequences. How individuals manage variability, change, and challenges have been the focus of formal thinking as far back as philosophers such as Omar Khayyam and Buddha.

The American Psychological Association's (APA) definition of adaptability is "the capacity to make appropriate responses to change or changing situations; the ability to modify or adjust one's behavior in meeting diverse circumstances or different people" (VandenBos, 2007, p. 17). In line with this definition, prevailing studies proposed and validated the scale of adaptability to measure people's ability and inclination to aptly modify psycho-behavioral tasks to face new, changing, and/or uncertain conditions and circumstances (Martin, Nejad, Colmar, \& Liem, 2013). The cited research was a cross-sectional construct validity study examining reliability, factor structure, and its correlations with academic and non-academic measures. The present paper builds on the aforementioned study and concludes that while adaptability capacity is predicted by personality traits (Martin, et al., 2013) and the implicit theories of ability ${ }^{1}$, it significantly predicts self-esteem, satisfaction with life (including job satisfaction), and meaning and purpose. Moreover, research shows that meaning in life (also known as meaning and purpose) is a mediator among religion, religiousness, life satisfaction, and well-being (Ardelt, 2003; Krok, 2014; Steger \& Frazier, 2005; Zika \& Chamberlain, 1992). This would indicate that meaning and purpose and adaptability are tightly linked which would have a salient effect on workplace satisfaction and performance (Krok, 2015).

The potential implications of this paper are multifold. First, it extends the behaviorally centered APA description of adaptability to also encompass cognitive and affective reactions to change and variability, bringing the concept in line with emerging tripartite (cognitive, affective, and be-

1 The implicit theories of ability personify people's beliefs about the essence of their own intelligence and abilities as either being fixed or flexible. 
havioral) frameworks (e.g., Fredricks, Blumenfeld, \& Paris, 2004). Second, it argues that since job performance and behavior are similar, then people's actions can be measured based on their ability and talent or level of contribution to their workplace (Campbell, McCloy, Oppler, \& Sager, 1993; Pulakos, Arad, Donovan, \& Plamondon, 2000). Third, the process of adaptability capacity development and activation (or commencement) is a continuous process and there is not much qualitative difference between the late teen years (for example age of 17 to 19) and the young adults (for example age 20 to 25). Therefore, it is appropriate to expand the Adaptability research finding to include young adults in the workplace (Araujo, \& Taveira, 2009; Porfeli, \& Lee, 2012). Fourth, meaning and purpose and religiosity have been loosely defined, and trivially (or deliberately) placed at odds in an attempt to give one a more divine notion and the other a philosophical status. Throughout this paper, the authors point out that meaning and purpose is an overarching concept that also includes religiosity. Fifth, a brief discussion about the predictors of adaptability and the unique role of adaptability affecting workplace (engagement and handling work stress) and non-workplace (e.g., self-esteem, life satisfaction, and performance) subjective well-being will also be given.

\section{Adaptability}

As previously mentioned, adaptability has been depicted as an individual's behavioral regulations and modifications to the novel, uncertain, variable, and changing situations and conditions in life (VandenBos, 2007). This approach was further developed by Martin and colleagues (2012) and Nejad (2014) to view adaptability as relevant cognitive, behavioral, and/or emotional adjustments when faced with life difficulties. Cognitive adjustment describes regulations in thinking processes to manage change, novel, and variable demands. Emotional adjustment is deemed as "emotional response-tendencies [that] may be modulated" (Gross, 1998, p. 3; see also Pekrun, 2012; Pekrun \& Stephens, 2009) to act in response to environmental change and variability. Behavioral adjustment suggests modifications in the behavioral range to manage new and changing life circumstances (Heckhausen, 1999; Heckhausen \& Schulz 1993; Tomasik, et al., 2010; Schulz \& Heckhausen, 1996). It is noteworthy to point out that behavior in the work environment could be defined as synonymous with job performance (Campbell, et al., 1993; Pulakos, et al., 2000) that is motivated by, inter alia, set and established goals. The goal-setting principle is a prominent framework for comprehending the interactions between motivated behaviors and performance (Latham, 2007). The fundamental proposition behind the goal-setting framework is that individuals transform motivational energy and urges into discernable actions through establishing and accomplishing goals. Therefore, workplace motivational forces such as monetary incentives, comradeship, and promotions can be translated into a significant part of workers' actions that are also referred to as job performance.

Goals are the systems that initiate motivation and hence form behavior. Furthermore, goals are helpful motivational mechanisms because they encourage behavioral arrays that could be beneficial to higher performance and success. Goals pilot individuals to fix attention, exercise endurance, persevere in the face of hardship, and take part in strategy development processes (Latham, 2007). Hinged on this trilateral (cognitive, affective, and behavioral) approach, Martin, Nejad, Colmar, and Liem (2014) developed the Adaptability construct and its measurement scale. The Adaptability Scale consisted of items that each comply with the following criteria: (a) proper intellectual, behavioral, or emotional regulation concerning (b) novelty, change, variability, and/or uncertainty that has (c) an effective purpose or result. Martin et al. (2014) also identified adaptability as a global factor that contains cognitive-behavioral and affective factors as consistent first-order factors that are negatively correlated with neuroticism but positively associated with enjoyment of school (or workplace), achievement, life satisfaction (including job satisfaction), and meaning and purpose.

The present article asserts that the adaptability findings which were drawn on the high school student sample can be extended to the young workers in the workplace environment. This extension is based on the hypothesis that the age difference between high school students and young workers would span over a few years which under ordinary circumstances and developmental trajectories would count for either no or a small variance at the most (Vuolo, Staff, \& Mortimer, 2012). Therefore, relevant to the suggested claim, the teenage years are the time for career path discovery and journey. This journey is an opportunity and obligation to learning about oneself and the environment including the work sphere (Super, 1960). Along with this self-discovery journey the notion of 'who I am' and 'what I will be doing in the future' become the existential focal point for young people. To this end, this self-discov- 
ery quest would include the self-identity discovery and definition. It is very much possible that the identity develops into an essential part of the development of meaning and purpose in life (Dittman-Kohli, \& Westerhof, 2000). Damon, Menon, and Bronk (2003) construed that both meaning and purpose are the essential developmental factors in every adolescents' 'growing up' process. Consequently, it is reasonable to suggest that adolescence is a significant period in the development of meaning and purpose in life and career path decisions.

The next two sections will discuss two significant concepts, Modes of Adaptation and Evolutionary Theorizing, that are relevant to the adaptability framework and conceptualization.

\section{Modes of Adaptation}

Literature and studies relevant to subjective well-being also examined how individuals adapt to negative and positive life situations. One dominant theory in this area is the adaptation framework of well-being (Diener, Lucas, \& Scallon, 2006). The adaptation theory is based on a self-regulating habituation framework in which people react to variabilities from their present adaptation level (see Diener et al., 2006). Diener and colleagues (2006) provided additional refinements to the adaptation theory that, first, individuals vary in the particular methods they employ to adjust. In the adaptability study, this is shown through differences in regulating thoughts, actions, and emotions when dealing with change and uncertainty. Second, the way in which individuals' approach to adaptation is different from one person to another that signals the need to explore inborn predictors (personality and implicit theories) of adaptability.

\section{Evolutionary Theorizing}

Evolutionary psychology's interpretation of the mind consists of psychological adaptations and the innate means for learning to endure by solving challenges that people encounter (Buss, 2005; Geary, 2008). Human Behavioral Ecology is rightfully a significant and relevant component of the evolutionary psychology discussion. Human behavioral ecology is an approach to 'functional' evolutionary theorizing (Barrett, Dunbar, \& Lycett, 2002) that claims relatively sudden changes in behavior occur over interactions with the environment in the process of adaptation (Smith, 2000). Human behavioral ecology, subsequently, has been depicted as a more practical approach to human adaptation and is bound to readily discernible changes in modern behavior and contexts (Caro, \& Borgerhoff Mulder, 1987). Indeed, it is this functional and pragmatic principle of evolutionary theorizing that aligns well with how we approach adaptability which proposes that a well-developed adaptability capacity provides individuals with immediate reactionary (or preemptive) self-regulatory skills and potentials to deal and manage life uncertain, variable, and challenging situations.

In brief, adaptability capacity is predicted by various presage factors and in turn, it predicts meaning and purpose, self-esteem, and life satisfaction that would ultimately affect performance in the workplace as well as in non-work-related life. Consequent$l y$, it is realistic and sound to suggest that adaptability plays a significant role not only in human development (physically and more so psychologically), but also, in the development of career path (Araujo, \& Taveira, 2009; Porfeli, \& Lee, 2012). The suggested role is significant because it influenc- es the formation of who one is and what one will be doing vocationally in the future through the development of meaning and purpose, and the positive self-esteem mindset. This claim, along with the other factors of subjective well-being outcome, which Adaptability also predicts, becomes the founding premises of this study.

\section{Adaptability and Process of Youth Development}

Based on the Buss and Cantor (1989) framework in the educational perspective, Martin et al. (2012) explored an adaptability process that suggests people's dispositional orientations impact the way they respond to their environmental demands that ultimately would affect their well-being in that environment.

The design of the adaptability research was a longitudinal one allowing researchers to manage prior variances in academic and non-academic well-being and examine how adaptability predicted positive and negative shifts in well-being. The hypothesized adaptability path model is depicted in Figures 1 and 2. As presented, adaptability predicts subjective well-being factors such as meaning and purpose, and satisfaction with life, among others. The next three sections will provide a deeper understanding of the Adaptability predictors and predicted factors.

\section{Adaptability Predictors: The Implicit Theories and Personality}

The two factors suggested in the adaptability model relevant to people's characteristic dispositions were the implicit theories of ability and personality. Arguably the most utilized personality frameworks were extraversion, neuroticism, agreeableness, conscientiousness, and openness 


\section{Figure 1}

Hypothesized model of adaptability: Socio-demographic and achievement covariates, personality and implicit theory predictors, and academic and non-academic well-being factors.

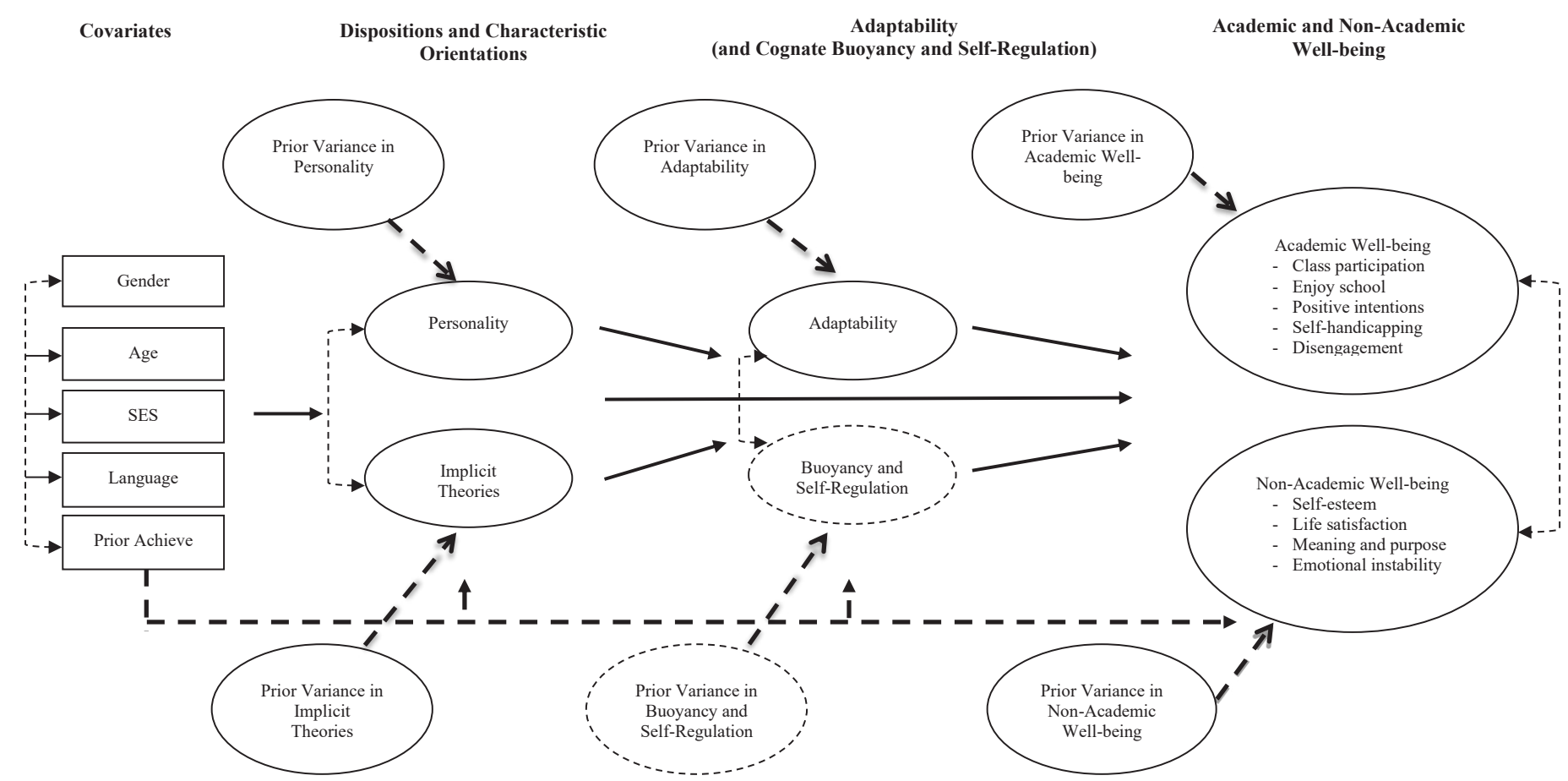

Notes. Bold lines represent paths of central interest. Dashed lines represent covariate parameters or correlations among factors; Dashed ellipse represents cognate factors to disentangle adaptability variance from buoyancy and self-regulation.

(McCrae \& Costa, 1985). In line with de Raad and Schouwenberg (1996), these personality factors (particularly extraversion, conscientiousness, and openness) were significant in the positive growth and adaptive modifications of one's personal resources (Baumeister, Gailliot, DeWall, \& Oaten, 2006). In recent measurement work, Martin et al. (2012) discovered adaptability significantly correlated with extraversion (.19), openness (.37), conscientiousness (.40), agreeableness (.44), and neuroticism (-.38).

The implicit theories assert that individuals' belief about intelligence and ability is divided into two camps, those who view intelligence as something that is fixed (an entity outlook) or those who view it as flexible (an 'incremental' outlook) (Dweck, 2000). Accordingly, people with an entity belief would view their ability as fixed and difficult to modify. In contrast, it might be suggested that individuals with an incremental outlook would view workplace well-being as something that can be negotiated through behavioral, emotional, and cognitive adjustments, thus becoming more inflexible towards psycho-behavioral adjustments.

En masse, it is reasonable to suggest that adolescents who hold an incremental view about their intelligence and ability would try their best to become better at what they do hence become a better worker who would benefit themselves, their colleagues, and their workplace.

\section{Well-being Factors}

In the context of adolescence, Martin et al. (2012) proposed that psycho-educational well-being includes positive and negative dimensions of academic well-being and non-academic well-being. Furthermore, concerning young workers and employees, the current study proposes that workplace well-being leads to more efficient performances and overall job satisfaction; (Pulakos, et al. 2000; Van Dam, Schipper, \& Runhaar, 2010; Tariq, Anwar, \& Aslam, 2011) which consist of both positive and negative dimensions of workplace well-being and non-workplace subjective well-being.

Relevant to the previous adaptability research and recent work concerning workplace subjective 
Figure 2

Hypothesized standardized beta paths significant at $p<.001$

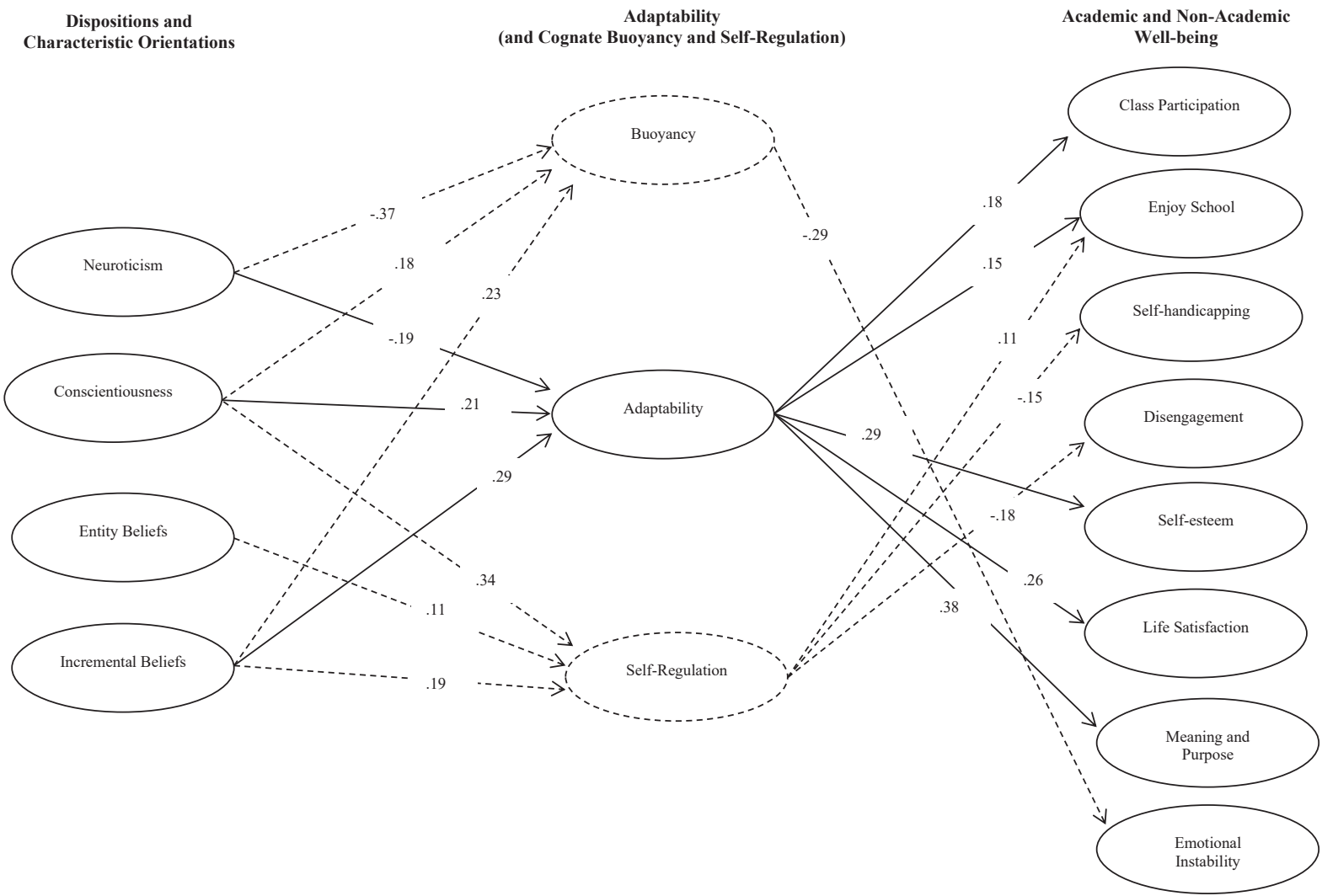

Notes: Dashed ellipses represent cognate factors to disentangle adaptability variance from buoyancy and self-regulation.

well-being, workers with ineffective or insufficient adaptability resources are prone to maladaptive work-related behavior and poor performance including stress, burnout, and anxiety (Cullen, Edwards, Casper, \& Gue, 2014). In terms of positive workplace well-being, research shows that a more developed adaptability capacity leads to a positive well-being repertoire which in turn manifests itself as low absenteeism, higher performance, and a healthier and more constructive relationship with managers (Collie, \& Martin, 2016; Pulakos, et al., 2000; Tariq, et al., 2011; Van Dam, et al., 2010). The following three sub-sections will provide relevant context about the well-being as well as meaning and purpose as the envisaged factors by adaptability construct.

\section{Positive Well-being}

From a life-span theory viewpoint, an enhanced sense of meaning and purpose is achieved through the sense of control gained from effectively and positively modifying thoughts and actions and participating in alternative paths and goals (Wrosch \& Scheier, 2003). Moreover, the improved competency to regulate cognitive, behavioral, and emotional repertoire is assumed to be associated with subjective well-being factors such as life satisfaction. For instance, purposeful modulations may result in goal attainment and fewer negative experiences, resulting in a higher sense of self-worth and perceived self-esteem (Wrosch \& Scheier, 2003). Studies have also correlated life satisfaction with a wider range of cognitive ability and resources (Fredrickson, 2001), and this improved wider range of competencies is aligned with the adaptability framework.

\section{Sense of Meaning and Purpose as a Positive Well-being Factor.}

Nietzsche said: "He who has a why to live for, can bear with almost any how" (Frankl, 1984, p.13) and Dostoevsky said: "There is only one thing that I dread: not to be worthy of my suffering" (Frankl, 1984, p.88). It was through these words and the time spent in Nazi concentration camps, including Auschwitz, Germany that Viktor Frankl (1905-1997) set the groundwork for his 'search for meaning' (Frankl, 1984). He asserted 
that suffering without purpose yields despair, hence, a person without purpose (and meaning) would succumb to agony and sorrow and fail to attain his/her genuine inner achievement (self-actualization). He argued that it is this spiritual free will, which is emancipatory and cannot be taken away by others, that makes life meaningful, spiritual, and purposeful. Consequently, Frankl suggests that people who develop a sense of meaning and purpose in life are inclined to be adaptable and equipped with the necessary resources to manage life difficulties.

Aligned with Frankl's view, adaptability has also been described as the capacity to manage difficulties with resilience (O'Connell, McNeely, \& Hall, 2007), and hence has become a significant constituent of workers' general skills that are referred to as meta-skills. Career meta-skills provide workers with the capacity, agency, and motivation to be malleable in the workplace (Hall, 2002; Hall \& Chandler, 2005). The sense of agency, or sense of control and awareness, is the idiosyncratic awareness of commencing, implementing, and managing one's wishful actions in the environment. It is this desired-based and purposive awareness force that stimulates the cognitive processes and promotes and executes physical/biological responses (Jeannerod, 2003). It is therefore hypothesized that the sense of agency and meaning at work drives young workers toward proactive goal-setting, excellence, achieving psychological happiness and success, and subsequently, improved performance.

Mohan and Uys (2006) suggest that people view life as a journey towards excellence, development, and growth. They also believe growth is achieved through the choices they make; hence, having meaning and purpose in life might give them direction to those choices. Moreover, growth is primarily seen in terms of personal, moral, and spiritual development of virtues which ultimately lead to an actualized person. An actualized person, in brief, would be an individual who possesses and practices what Zoroaster professed as Good Thoughts, Good Words, and Good Deeds (Dhalla, 1997). Additionally, Maslow (1968) believes an actualized person is a person who has fulfilled his/her basic as well as psychological needs; thus, such a person would behave in a manner that benefits others around him/her as well.

Clinical research has evinced that the underdeveloped sense of meaning and purpose in early life would present individuals with significant difficulty to procure motivational belief systems and vigor later in life (Erikson, 1968; Marcia, 1980). The significant and relevant studies on purpose have employed the PIL (Purpose in Life) measure (Crumbaugh \& Maholick, 1967) to investigate the effects of having a purpose in life not only on the psychological as well as emotional means but also on people's interactions with their environment including social actions. Those studies implied that high scores on the PIL are positively correlated with loyalty to social action (including workplace activities) and mediated the association between happiness and spirituality (Butler \& Carr, 1968; French, \& Joseph, 1999). On the other hand, low scores on the PIL measure correlated with involvement in antisocial activities, lack of interest, and alcohol as well as drug use and abuse (Sappington \& Kelly, 1995; Waisberg \& Porter, 1994; Noblejas de la Flor, 1997). Moreover, another study also found that people with a healthy and compelling sense of meaning and purpose in life would experience fewer psychological struggles, and enjoy greater happiness overall (Ryff \& Singer, 1998).

Finding meaning and purpose in life could, then, be described similarly to acquiring a roadmap that would not only provide directions but also indicate a clear destination. Meaning and purpose are the roadmap for personal growth and development, including the performance at work (the directions), which would bring happiness and self-contentment to a person (the destination) (Bronk, 2013). Those (including workers and employees) who seek personal growth and development towards a higher power are likely to do their best in all aspects of their lives (including work or job performance) to become worthy of the ultimate union with the higher power (Bronk, 2013).

\section{Negative Non-workplace Well-being}

Life-span control studies contend that incapacity to negotiate alternative means to deal with unattainable goals and poor self-regulation is correlated with psychological stress and mediocre mental health results (Wrosch, Scheier, Miller, Schulz, \& Carver, 2003). Poor mental health can be encapsulated in the form of emotional instability. Emotional instability implies people's irritability, fear, emotional uncertainty, and inclination to be worried and anxious (Marsh, 2007). It may cause people to be more vulnerable to mental as well as physical illnesses such as anxiety, depression, worrying, heart problems, stroke, and the like (Kubzansky \& Kawachi, 2000). 
Correlations Relevant to Adaptability and the Well-being Factors

The adaptability study by Martin et al. (2012) showed significant correlations between adaptability and a number of outcome factors (e.g., academic well-being outcome factor) including positive intent $(r=$ $.57, p<.001)$ and disengagement $(r=$ $-.50, p<.001)$. As for non-academic well-being factors, it showed significant correlations between adaptability and self-esteem $(r=.61, p<.001)$, life satisfaction $(r=.58, p<.001)$, meaning and purpose $(r=.53, p<$ $.001)$, and emotional instability $(r=$ $-.21, p<.001)$. Furthermore, Chan and Mai (2015) have shown that adaptability positively predicted satisfaction with work (job satisfaction), engagement with work, and positive intent, and negatively predicted self-handicapping, absenteeism, and disengagement.

The research on workplace subjective well-being also indicated that workers who possess a positive adaptive repertoire would manage work challenges, variations, uncertainties, and changes more effectively and efficiently (Griffin, Neal, \& Parker 2007). It has also been asserted that the ability to manage workplace challenges and uncertainties effectively using the adaptability of personal resources would lead to higher and more positive workplace subjective well-being (Luhmann, Hofmann, Eid, \& Lucas, 2012). Workplace subjective well-being has been argued to include meaning and purpose along with other aforementioned factors. Meaning and purpose (which includes religiosity in most cases (Krok, 2014; Chamberlain, \& Zika, 1992) is suggested to influence and affect people's work performance and attitudes toward work and work environments. More- over, research confirms that meaning in life is a mediator between:

- religion and well-being (Krok, 2014; Chamberlain, \& Zika, 1992),

- intrinsic religious orientation (a belief that views religion as an end in itself and a master motivational force) and subjective well-being (Ardelt, 2003), and - religiousness and life satisfaction (Steger, \& Frazier, 2005).

Consequently, it is plausible to claim that meaning and purpose, and adaptability are tightly connected, and this relationship would have a salient effect on workplace satisfaction and performance (Krok, 2015).

It is through this mutual dialogue between a worker's view of self and the path toward an actualized self that workers learn to acquire further work ethics and perform to the best of their ability. As a result, a self-actualized person who has meaning and purpose in her/his life would work toward becoming the best he/she can be so that he or she can reach a holistic existence.

Taken together, as hypothesized, findings indicated that implicit theories of ability and personality have predicted adaptability. Also, as posited, adaptability predicted academic (also extended to the workplace) and non-academic (nonwork related) well-being. Importantly, adaptability explained variance in well-being after considering the influence of prior achievement, personality, socio-demographics, implicit theories of ability, and buoyancy and self-regulation.

\section{Adaptability, Subjective Well-being, and Meaning and Purpose}

For workplace subjective well-being, it is shown that adaptable workers are presumed to be more determined in their future goals (positive intent), more competent to manage the fast pace and uncertain nature of their work (work participation), experience greater work-related subjective well-being (workplace enjoyment), and be less motivated to navigate defensively (self-handicapping) or giving up (disengagement) (Collie, \& Martin, 2016; Martin et al., 2012; Pulakos, et al., 2000; Tariq, et al., 2011; Van Dam, et al., 2010). For non-workplace subjective well-being, the authors drew on life-span and adaptation contexts to claim that adaptability positively predicts subjective well-being (Diener et al, 2006), sense of purpose (also spirituality and religiosity) (Wrosch, et al., 2003), and negatively predicts psychological upset (Wrosch, Scheier, Miller, et al., 2003).

Following these suppositions, adaptability firmly predicted these well-being factors (including meaning and purpose) in the expected positive direction. Research shows that meaning in life, personal meaning, and spirituality are mediators between religious coping and psychological well-being (Krok, 2015). Furthermore, adaptability significantly facilitated the relationship between personality and well-being and between incremental beliefs and well-being. Importantly, it showed specific variation over and above the cognate academic factors of self-regulation and buoyancy. Thus, beyond the scope of the regulatory features of self-regulation and the adversity-related components of buoyancy, people's cognitive, behavioral, and/or emotive 
modulations to novelty and change take a specific role in their well-being including meaning and purpose.

\section{Personality as a Predictor of Adaptability}

The strongest personality factors of adaptability were agreeableness, conscientiousness, and neuroticism (negatively). Furthermore, adaptability strongly facilitated and influenced the relationship between these three personality constructs and well-being. In essence, although adaptability has a significant direct path to well-being, it also predicts it indirectly at $p<.001$ more significantly than the personality construct that has a direct path to well-being at $p<.001$. Moreover, multivariate regression analysis extended the correlational work by Martin et al. (2012) that presented the relationship between all personality factors with adaptability. Consequently, it seems that some people are innately better equipped with adaptability resources than others. This is noteworthy because such a finding will influence interventions developed to encourage and maintain adaptability capacity. For individuals who may be low in conscientiousness and agreeableness or high in neuroticism, we point to the review by Ginns and colleagues (2011) who argued how people can be taught to change the level, nature and/ or degree of behavior, and cognitive and affective repertoires that might leave them trapped. Therefore, it will be beneficial to practitioners to understand people's personality profile when they design adaptability interventions.

\section{Implications for Intervention}

Adaptability can be addressed in similar ways that adversity constructs have been studied. For example, Morales (2000) suggested a resilience cycle that is focused on maintaining people's capacity to face risk continuously under work-related stress and burnouts are such examples. Adopting this view, adaptability intervention may consist of the following:

- Workers are trained on how to acknowledge change and variability, realistically and efficiently, at the workplace that might necessitate adaptability.

- Workers are trained on how to exercise appropriate regulations to behavior, emotion, and/or thinking process using existing personal resources mediated by meaning and purpose.

- These adaptations help workers and employees to manage change.

- Workers are inspired to realize the merits of these regulations and then enhance and/or improve them.

- Workers are encouraged to search for purpose in their work-life, and the means to realize and achieve them.

- These ongoing modifications and improvements of cognitive, behavioral, and/or emotional regulations may strengthen people's ability to face ongoing change, variability, novelty, and uncertainty in workplace and non-workplace life subjective well-being.

Additionally, adaptability interventions need to consider the role of meaning and purpose and within that framework - the role of spirituality. There is a long history of cognitive-behavioral and emotional intervention studies indicating that workers can modify behavior, emotion, and cognition to more success- fully function in the relevant performance sphere (e.g., Craven, Marsh, \& Debus, 1991; Hattie, 2009; McInerney, McInerney, \& Marsh 1997; O'Mara, Marsh, Craven, \& Debus, 2006). These targeted interventions may be the foundations that produce the type of adjustments required to constructively respond to change, novelty, variability, uncertainty, and stress in the workplace.

Learning more about the inherent relationship between adaptability capacity and fluency in the young workforce and workplace performance is salient to workforce-management and profitable business efforts and strategies. This current study enables managers and industry leaders to better understand their workforce, and how to motivate them to achieve more productive results.

The potential implications of this paper were multifold. First, it extended the behaviorally-centered APA description of adaptability to also encompass cognitive and affective reactions to change and variability, bringing the concept in line with emerging tripartite (cognitive, affective, and behavioral) frameworks. This wisdom is essential for business managers and leaders since it will allow for more focused workforce motivation and job enhancement policies. Those policies that aim at the young workers' personal and professional growth as a person and as a worker may ultimately lead to a mutually beneficial relationship between businesses and the workers. Knowing that young workers are capable of developing and activating their adaptability resources, which can lead to positive subjective well-being, therefore, more enhanced performance, managers can potentially build stronger working alliances and increase productivity and lower the rate of job dissatisfaction among their 
young workforce. Second, it argued that since job performance and behavior are similar, then people's actions can be measured based on their ability and talent or level of contribution to their workplace (Campbell, McCloy, Oppler, \& Sager, 1993; Pulakos, Arad, Donovan, \& Plamondon, 2000). Consequently, such insight provides career counselors and managers with measurable and workable instruments that they can use to understand and apply the psychological and behavioral plans and policies that may assist their young workforce (which inherently is more plastic and malleable) to achieve their potentials (personally and professionally). Third, the process of adaptability capacity development and commencement is a progressive process where there is not much qualitative distinction between the late teen years and the young adults. For that reason, it is appropriate to broaden the Adaptability research finding to include young adults in the workplace (Araujo, \& Taveira, 2009; Porfeli, \& Lee, 2012). This implies that the workplace policies and career development research and counseling trajectories can benefit from the considerable amount of the existing research that has been conducted about youth (adolescents) performance, engagement, resilience, and adaptability to facilitate the young people's vocational path growth and development. Fourth, meaning and purpose and religiosity have been loosely defined and trivially (or wittingly) placed at odds in an attempt to give one a more celestial perception and the other a philosophical status. However, informed by a significant number of relevant research, the current paper argued that meaning and purpose is an overarching concept that also includes religiosity. Furthermore, the current paper also showed that spirituality, the enhanced sense of self-actualization, happiness, life satisfaction, positive view of self-esteem, enhanced performance, positive belief of subjective well-being, and adaptability are either directly or indirectly correlate. Taken together, such wisdom provides an effective instrument in the hands of business leaders to make policies that promote adaptability development. Moreover, this insight also gives an edge to the vocational development counselors and practitioners so they can equip their clients with such an effective and applicable tool to overcome workplace impediments and consequently excel in their careers and life.

\section{Future Directions}

In keeping with adversity-related research, it is significant to understand the collective effect of change. For instance, is there a crucial point where excessive change introduces adversity - and would this indicate the need for coping, buoyancy $^{2}$, and resilience capacity? Also, while the adaptability study focused on students from schools and their academic settings, would a workplace study yield similar results?

It is also worth mentioning that the Adaptability Scale is not a domain-specific measurement construct relevant to a particular context, but it is a domain-general construct. Conceivably the more intense the measure is on a specific domain, the more it might predict well-being factors in that sphere. Further, a more focused study must investigate the relationship between adaptability and spirituality as an overarching factor in that domain.

2 Buoyancy is people's capacity to effectively manage predicaments and obstacles that are part of everyday life (Martin \& Marsh, 2007).
Relevant to methodology, the adaptability research was a quantitative study that sets limitations in terms of what could be comprehended through the data. Future research might involve a qualitative method to further understand when and how adaptability may function and how it specifically predicts spirituality and religiosity, and their relevance to the workplace and workers' performance. Finally, although the adaptability study had adopted a variable-focus approach to this construct, future investigations might employ person-focused approaches. This would involve identifying groups of workers deemed as adaptable (or not) with a perspective on identifying elements that define their group membership. This has the benefit of investigating patterns of adaptability taking place 'naturally' and may also grant chances for further in-depth case study investigations.

\section{Conclusion}

Adaptability is defined as proper modulations in cognition, behavior, and/or affect in dealing with life's new, changing, variable, and/or uncertain circumstances. The present study briefly discussed the dispositional predictors of adaptability and ways in which adaptability predicts workplace subjective well-being (engagement, performance, and handling work stress). It also discussed the ways adaptability predicts non-workplace subjective well-being (self-esteem, life satisfaction, meaning and purpose including spirituality, and emotional instability). Furthermore, a discussion about the positive effects of meaning and purpose on workers (in terms of job and work-life satisfaction, and performance) and its beneficial effects on both workers and organizations was provided. The re- 
sults provide theoretical and empirical implications for scholars and practitioners striving to better comprehend responses to the change and variability that are a reality in the world of workers and employees. This study enables managers and industry leaders to better understand their young workforce, and how to motivate them to achieve more productive results. It is through such wisdom and the understanding and recognition of their young workers' potentials that the leaders and managers can build a trusting, collaborative, and mutually respectful relationship with them to create a strong, professional, and yet, profitable working alliances with their younger workforce that would transform into a win-win resolution for many years to come.

\section{References}

Araújo, A. M., \& Taveira, M. C. (2009). Study of career development in children from a developmental-contextual perspective. European Journal of Education and Psychology, 2(1), 49-67.

Ardelt, M. (2003). Empirical assessment of a three-dimensional wisdom scale. $R e$ search on Aging, 25(3), 275-324. https://doi. org/10. 1177/0164027503025003004

Barrett, L., Dunbar, R., \& Lycett, J. (2002). Human evolutionary psychology. New York: Palgrave.

Baumeister, R. F., Gailliot, M., DeWall, C. N., \& Oaten, M. (2006). Self-regulation and personality: How interventions increase regulatory success, and how depletion moderates the effects of traits on behavior. Journal of Personality 74, 6.

Bronfenbrenner, U. (2001). The bioecological theory of human development. In N.J. Smelser \& P.B. Baltes (Eds). International encyclopedia of the social and behavioral sciences, Vol 10. New York: Elsevier.

Bronk, K. C. (2013). Purpose in life: A component of optimal youth development. New York: Springer.

Buss, D. M. (2005). Handbook of evolutionary psychology. Hoboken, NJ: Wiley.

Buss, D. W., \& Cantor, N. (1989). Personality psychology: Recent trends and emerging directions. New York: Springer-Verlag.

Butler, A. C., \& Carr, L. (1968). Purpose in life through social action. Journal of Social Psychology, 74 (2), 243-250.

Campbell, J. P., McCloy, R. A., Oppler, S. H. \& Sager, C.E. (1993). A Theory of Performance. In: Schmitt, N. and Borman, W.C., Eds., Personnel Selection in Organizations, Jossey-Bass, San Francisco, (pp. 35-70).

Caro, T. M., \& Borgerhoff Mulder, M. (1987). The problem of adaptation in the study of human behavior. Ethology and Sociobiology, 8, 61-72

Chamberlain, K., \& Zika, S. (1992). Religiosity, meaning in life, and psychological well-being. In J. F. Schumaker (Ed.), Religion and mental health (pp. 138-148). New York, NY: Oxford University Press.

Collie, R. J., \& Martin, A. J. (2016). Adaptability: An Important Capacity for Effective Teachers. Educational Sciences: Practice and Theory. 38(1): 27-39. doi: 10.7459/ept/38.1.03.

Craven, R. G., Marsh, H. W., \& Debus, R. L. (1991). Effects of internally focused feedback and attributional feedback on the enhancement of academic self-con- cept. Journal of Educational Psychology, 83, 17-26.

Crumbaugh, J. C., \& Maholick, L. T. (1967). An Experimental Study in Existentialism: The Psychometric Approach to Frankl's Concept of Noögenic Neurosis. In V. E. Frankl (Ed.), Psychotherapy and existentialism (pp. 183-197). New York: Simon and Schuster.

Cullen, K. L., Edwards, B. D., Casper, W. C. \& Gue, K. R. (2014). Employees' Adaptability and Perceptions of Change-Related Uncertainty: Implications for Perceived Organizational Support, Job Satisfaction and Performance. Journal of Business and Psychology 29, 269-280. https:// doi.org/10.1007/s10869-0139312-y

Damon, W., Menon, J., \& Bronk, K. C. (2003). The development of purpose during adolescence. Applied Developmental Science, 7 (3), 119-128.

de Raad, B., \& Schouwenburg, H. C. (1996). Personality in learning and education: A review. European Journal of Personality, 10 , 303-336.

Dhalla, M. N. (1997). History of Zoroastrianism, Bombay: K. R. Cama Oriental Institute.

Diener, E., Lucas, R., \& Scollon, C. N. (2006). Beyond the hedonic treadmill: Revising the adaptation theory of well-being. American Psychologist, 61, 305-314.

Dittmann-Kohli, F., Westerhof, G. J. (2000). The personal meaning system in a lifespan perspective. In G. T. Reker, K. Chamberlain, (Eds.), Exploring existential meaning: Optimizing human development across the lifespan (pp. 107-123). Thousand Oaks, CA: Sage.

Dweck, C.S. (2000). Self-theories: 
Their role in motivation, personality and development. Philadelphia: Psychology Press.

Erikson, E. H. (n.d.). Identity: Youth and Crisis. W.W.Norton.

Frankl, V. E. 1. (1984). Man's search for meaning. Washington Square Press.

Fredricks, J. A., Blumenfeld, P. C., \& Paris, A. H. (2004). School engagement: potential of the concept, state of the evidence. Review of Educational Research, 74, 59-109.

Fredrickson, B. L. (2001). The role of positive emotions in positive psychology. American Psychologist, 56, 218-226.

French, S., \& Joseph, S. (1999). Religiosity and its association with happiness, purpose in life, and self-actualisation. Mental Health, Religion, and Culture, 2, 117-120.

Geary, D. C. (2008). An evolutionarily informed education science. Educational Psychologist, 43, 179-195.

Ginns, P., Liem, G. A. D., \& Martin, A. J. (2011). The role of personality in learning processes and learning outcomes in applied settings. In S. Boag \& N. Tiliopoulos (Eds). Personality and individual differences: Theory, assessment, and application. New York: Nova Science Publishers.

Griffin, M. A., Neal, A., \& Parker, S. K. (2007). A New Model of Work Role Performance: Positive Behavior in Uncertain and Interdependent Contexts. Academy of Management Journal, 50(2), 327-327. doi: 10.5465/ amj.2007.24634438

Gross, J. J. (1998). The emerging field of emotion regulation: An integrative review. Review of General Psychology, 2, 271-299.
Hall, D. T. (2002). Careers in and out of organizations. Thousand Oaks, CA: Sage.

Hall, D. T., \& Chandler, D. E. (2005). Psychological success: When the career is a calling. Journal of Organizational Behavior, 26, 155-176.

Hattie, J. (2009). Visible learning: A synthesis of over 800 meta-analyses relating to achievement. London: Routledge.

Heckhausen, J. (1999). Developmental regulation in adulthood: Age-normative and socio-structural constraints as adaptive challenges. New York: Cambridge University Press.

Heckhausen, J., \& Schulz, R. (1993). Optimization by selection and compensation: Balancing primary and secondary control in lifespan development. International Journal of Behavior Development, 16, 287-303.

Hofäcker, D., Buchholz, S., \& Blossfeld, H. P. (2010). Globalization, institutional filters and changing life course patterns in modern societies. A summary of the results from the GLOBALIFE-project. In R. K. Silbereisen $\&$ X. Chen (Eds.), Social change and human development: Concept and results (pp. 101-124). London: Sage Publications.

Jeannerod, M. (2003). The mechanism of self-recognition in humans. Behavioural Brain Research, 142(1-2), 1-15. doi:10.1016/s01664328(02)00384-4

Krok, D. (2014). The mediating role of coping in the relationships between religiousness and mental health. Archives of Psychiatry and Psychotherapy, 16(2), 5-13. doi: 10.12740/APP/26313

Krok, D. (2015). The role of meaning in life within the relations of religious coping and psychological well-being. Journal of Religion and Health, 54(6), 2292-2308. doi: 10.1007/ s10943-014-9983-3

Kubzansky, L. D., Kawachi, I. (2000). Going to the heart of the matter: do negative emotions cause coronary heart disease? Journal of Psychosomatic Research 48, 323-337.

Latham, G. P. (2007). Work motivation: History, theory, research, and practice. Thousand Oaks, Calif.: Sage Publications.

Luhmann, M., Hofmann, W., Eid, M., \& Lucas, R. E. (2012). Subjective well-being and adaptation to life events: A meta-analysis. Journal of Personality and Social Psychology, 102(3), 592615. https://doi.org/10.1037/ a0025948

Marcia, J. E. (1980). Identity in adolescence. In J. Adelson (Ed.), Handbook of adolescent psychology (p. 159-187). New York, NY: Wiley.

Marsh, H.W. (2007). Self-concept theory, measurement, and research into practice: The role of self-concept in educational psychology. Leicester, UK: British Psychological Society.

Martin, A.J., Nejad, H., Colmar, S., \& Liem, G. A. D. (2012). Adaptability: Conceptual and empirical perspectives on responses to change, novelty and uncertainty. Australian Journal of Guidance and Counselling, 22, 58-81.

Martin, A. J., Nejad, H. G., Colmar, S., \& Liem, G. A. D. (2013). Adaptability: How students' responses to uncertainty and novelty predict their academic and non-academic outcomes. Journal of Educational Psychology, 105(3), 728-746. https://doi. org/10.1037/a0032794 
Martin, A. J., Nejad, H. G., Colmar, S., \& Liem, G. A. D. (2014). From measurement to modeling: A case study of the development and implementation of the adaptability scale. London: Sage.

Maslow, A. (1968). Some Educational Implications of the Humanistic Psychologies. Harvard Educational Review, 38(4), 685696. doi:10.17763/haer.38.4. j07288786v86w660

McCrae, R. R., \& Costa, P. T. (1985). Updating Norman's "adequate taxonomy": Intelligence and personality dimensions in natural language and in questionnaires. Journal of Personality \& Social Psychology, 49, 710-721.

McInerney, V., McInerney, D. M., \& Marsh, H. W. (1997). Effects of metacognitive strategy training within a cooperative group learning context on computer achievement and anxiety: An aptitude-treatment interaction study. Journal of Educational Psychology, 89, 686-695.

Mohan, D. L., \& Uys, J. S., (2006).

'Towards living with meaning and purpose: Spiritual perspectives of people at work', $S A$ Journal of Industrial Psychology 32(1), 53-59. http://dx.doi. org/10.4102/sajip.v32i1.228

Morales, E. E. (2000). A contextual understanding of the process of educational resilience: High achieving Dominican American students and the 'Resilience $\mathrm{Cy}$ cle'. Innovative Higher Education, 25, 7-22.

Nejad, H. (2014). Adaptability in youth: components, predictors, and consequences. [Doctoral dissertation, the University of Sydney, Australia]. https://ses. library.usyd.edu.au/bitstream/ handle/2123/11548/Ghase- mi Nejad \%20M\%20N Thesis. pdf? is Allowed $=\mathrm{y} \&$ sequence $=4]$.

Noblejas de la Flor, M. A. (1997). Meaning levels and drug abuse therapy: An empirical study. International Forum for Logotherapy, 20 (1), 46-51.

O'Connell, D. J., McNeely, E., \& Hall, D. T., (2007). Unpacking Personal Adaptability at Work. Journal of Leadership \& Organizational Studies 14(3) 248-259/ doi: 10.1177/1071791907311005

O’Mara, A. J., Marsh H. W., Craven, R. G., \& Debus, R. (2006). Do self-concept interventions make a difference? A synergistic blend of construct validation and meta-analysis. Educational Psychologist, 41, 181-206.

Pekrun, R. (2012). Emotion regulation. In N. Seel (Ed.), Encyclopedia of the Sciences of Learning. New York: Springer.

Pekrun, R., \& Stephens, E. J. (2009). Goals, emotions, and emotion regulation: Perspectives of the control-value theory of achievement emotions. Human Development, 52, 357-365.

Pinquart, M., \& Silbereisen, R. K. (2004). Human development in times of social change: Theoretical considerations and research needs. International Journal of Behavioral Development, 28 , $289-298$.

Porfeli, E. J., \& Lee, B. (2012). Career development during childhood and adolescence. New directions for youth development, 2012(134), 11-22. doi:10.1002/yd.20011.

Pulakos, E. D., Arad, S., Donovan, M. A., \& Plamondon, K. E. (2000). Adaptability in the workplace: Development of a taxonomy of adaptive performance. Journal of Applied Psychology, 85(4),
612-624. doi: 10.1037/00219010.85.4.612

Ryff, C. D., \& Singer, B. (1998). The contours of positive human health. Psychological Inquiry, 9 (1), 1-28.

Sappington, A. A., \& Kelly, P. J. (1995). Self-perceived anger problems in college students. International Forum for Logotherapy, 18, 74-82.

Schulz, R., \& Heckhausen, J. (1996). A life span model of successful aging. American Psychologist, 51, 702-714.

Smith, E.A. (2000). Three styles in the evolutionary analysis of human behavior. In L. Cronk \& N.A. Chagnon (Eds). Adaptation and human behavior: An anthropological perspective. pp. 27-46. Piscataway, NJ: Aldine Transaction.

Steger, M. F., \& Frazier, P. (2005). Meaning in Life: One Link in the Chain from Religiousness to Well-Being. Journal of Counseling Psychology, 52(4), 574-582. doi: 10.1037/00220167.52.4.574

Super, D. E. (1960). The Critical Ninth Grade: Vocational Choice or Vocational Exploration. The Personnel and Guidance Journal, 39(2), 106-109. doi:10.1002/j.2164-4918.1960. tb01854.x

Tariq, M. R., Anwar, M. S., Aslam, M. (2011). Impact of Employee Adaptability to Change towards Organizational Competitive Advantage. Global Journal of Management and Business Research, 11(7).

Tomasik, M. J., \& Silbereisen, R. K. (2009). Demands of social change as a function of the political context, institutional filters, and psychosocial resources. Social Indicators Research, 94, 
$13-28$.

Tomasik, M. J., Silbereisen, R. K., \& Heckhausen, J. (2010). Is it adaptive to disengage from demands of social change? Adjustment to developmental barriers in opportunity-deprived regions. Motivation and Emotion, 34, 384-398.

Van Dam, K., Schipper, M., \& Runhaar, P. (2010). Developing a competency-based framework for teachers' entrepreneurial behaviour. Teaching and Teacher Education, 26(4), 965-971.

VandenBos, G. R. (2007) (Ed). American Psychological Association Dictionary of Psychology. Washington DC: American Psychological Association.

Vuolo, M., Staff, J., \& Mortimer, J. T. (2012). Weathering the great recession: Psychological and behavioral trajectories in the transition from school to work. Developmental Psychology, 48(6), 1759-1773. https:// doi.org/10.1037/a0026047

Waisberg, J. L., \& Porter, J. E. (1994). Purpose in life and outcome treatment for alcohol dependence. British Journal of Clinical Psychology,33, 49-63.

Wrosch, C., \& Scheier, M. F. (2003). Personality and quality of life: The importance of optimism and goal adjustment. Quality of Life Research, 12, 59-72.

Wrosch, C., Scheier, M. F., Miller, G. E., Schulz, R., \& Carver, C. S. (2003). Adaptive self-regulation of unattainable goals: Goal disengagement, goal reengagement, and subjective well-being. Personality and Social Psychology Bulletin, 29, 1494-1508.

Zika, S., \& Chamberlain, K. (1992). On the relation between meaning in life and psychological well-being. British Journal of
Psychology, 83(1), 133-145. doi: 10.1111/j.2044-8295.1992.

tb02429.x 